\title{
Is There a Role for Uncertainty in Forecasting Output Growth in OECD Countries? Evidence from a Time Varying Parameter-Panel Vector Autoregressive Model
}

\author{
Goodness C. Aye ${ }^{*}$, Rangan Gupta ${ }^{* *}$, Chi Keung Marco Lau ${ }^{* * *}$ and Xin Sheng ${ }^{* * * *}$
}

\begin{abstract}
This paper uses a time varying parameter-panel vector autoregressive (TVP-PVAR) model to analyze the role played by domestic and US news-based measures of uncertainty in forecasting the growth of industrial production of twelve Organisation for Economic Co-operation and Development (OECD) countries. Based on a monthly out-of-sample period of 2009:06 to 2017:05, given an in-sample of 2003:03 to 2009:05, there are only 46 percent of cases where domestic uncertainty can improve the forecast of output growth relative to a baseline monetary TVP-PVAR model, which includes inflation, interest rate and nominal exchange rate growth, besides output growth. Moreover, including US uncertainty does not necessarily improve the forecasting performance of output growth from the TVP-PVAR model that includes only the domestic uncertainty along with the baseline variables. So, in general, while uncertainty is important in predicting the future path of output growth in the twelve advanced economies considered, a forecaster can do better in majority of the instances by just considering the information from standard macroeconomic variables.
\end{abstract}

Keywords: Economic Uncertainty, Output Growth, Time Varying Parameter, Panel Vector Autoregressions, OECD Countries.

JEL Codes: C33, C53, E32, E37, E60.

\footnotetext{
* Department of Economics, University of Pretoria, Pretoria, 0002, South Africa. Email: goodness.aye@ gmail.com.

** Corresponding author. Department of Economics, University of Pretoria, Pretoria, 0002, South Africa. Email: rangan.gupta@up.ac.za.

Huddersfield Business School, University of Huddersfield, Huddersfield, HD1 3DH, United Kingdom. Email: c.lau@hud.ac.uk.

* Huddersfield Business School, University of Huddersfield, Huddersfield, HD1 3DH, United Kingdom. Email: x.sheng@hud.ac.uk.
} 


\section{Introduction}

Following the "Great Recession" there has been a renewed interest in the link between uncertainty and the macroeconomy, using both theoretical and empirical approaches (see Gupta et al., (2018, forthcoming) for detailed literature reviews in this regard). Overall, this line of research tends to overwhelmingly confirm the negative impact of uncertainty on economic activity. Interestingly, barring a few exceptions (Karnizova and Li, 2014; Balcilar et al., 2016; Junttila and Vataja, 2017; Pierdzioch and Gupta 2017; Segnon et al., forthcoming), empirical studies trying to recover the link between uncertainty and economic activity have been in-sample structural analyses, concentrating on the US, the UK or the aggregate Euro area.

Karnizova and Li (2014) use probit models to highlight the role of uncertainty in forecasting U.S. recessions, while Balcilar et al., (2016) emphasize the gains from using mixed-frequency Markovswitching models that includes uncertainty in forecasting U.S. recessions. ${ }^{1}$ Junttila and Vataja (2017) show that inclusion of uncertainty for either the U.S., the UK, or the overall Euro area improves the forecasting ability of benchmark predictive regression models that contain standard financial market information, especially for the period before the 2008 global financial crisis. Unlike the above mentioned three studies, which concentrate on post-World War II data, Segnon et al., (forthcoming) forecast quarterly U.S. GNP over the period from 1900 to 2014 using various linear and nonlinear bivariate models featuring uncertainty. They show that, while a Markov-switching time-varying parameter vector autoregressive (MS-TVP-VAR) model in most cases cannot be outperformed by its competitors when point forecasts are being studied, a Bayesian VAR (BVAR) model with stochastic volatility is the best-performing model in the majority of the cases for density forecasts. Finally, Gupta and Pierdzioch (2017) use a Boosted Regression Trees (BRT) approach to study the potentially nonlinear link between various standard predictors, components of uncertainty, and U.S recessions over the monthly period of 1889 to 2016. An analysis based on receiver-operatingcharacteristic (ROC) curves showed that including war-related uncertainty in the list of predictors improves out-of-sample forecasting performance at a longer-term forecasting horizon; however, the predictive value of this component relative to other components of uncertainty has declined in the second half of the 20th century. In general, the above-mentioned time-series based country-specific studies dealing with forecasting exercises, does suggest that uncertainty contains useful information in predicting economic activities over out-of-sample periods.

There is a widely held view that the importance of variables and models should be judged based on out-of-sample validations (Campbell, 2008). Given this line of thinking, and against this backdrop of (limited) evidence on the out-of-sample forecasting performance of uncertainty with respect to subsequent developments of economic activity only restricted to the aggregate Euro area, besides the US and the UK, we, in this paper for the first-time, use a Time Varying Parameter-Panel Vector Autoregressive (TVP-PVAR) model (Koop and Korobilis, 2015) to analyze the ability of uncertainty to forecast movements of output in twelve Organisation for Economic Co-operation and Development (OECD) countries (Australia, Canada, France, Germany, Ireland, Italy, Japan, South Korea, the Netherlands, Spain, Sweden, and the UK). Note that, the US is left out, since we not only analyze the impact of the domestic uncertainty of these economies, but also the possible role played by the uncertainty of the US economy (Colombo, 2013; Jones and Olson, 2015), given its dominance in the world economic structure, on the growth of these twelve OECD countries. In an increasingly globalized world, where macroeconomic events in one country can spill over to another country, the need for models which accommodate such interlinkages is, understandably, an obvious choice over time-series approaches, with the need being fulfilled by a PVAR framework which jointly models many macroeconomic variables in many countries. The TVP-PVAR, being a

\footnotetext{
${ }^{1}$ Balcilar et al., (2017) use bivariate long-memory models to show that uncertainty can also forecast U.S. inflation in an effective manner compared to short-memory models.
} 
time-varying approach based on Dynamic Model Averaging (DMA) and Dynamic Model Selection (DMS), controls for the nonlinear relationship between uncertainty and economic activity (Balcilar et al., 2016; Pierdzioch and Gupta, 2017), but also allows for heterogenous coefficients (slopes or responses) across the equations of each of the cross-sectional units, i.e., the twelve countries. The remainder of the paper is organized as follows: Section 2 presents the methodology, while Section 3 discusses the data and results, with Section 4 concluding the paper.

\section{Methodology}

Recently, Koop and Korobilis (2015) developed econometric methods for estimating large Bayesian time-varying parameter panel vector autoregressions (TVP-PVARs) with time-varying error covariances. Large TVP-PVARs contain huge numbers of parameters which can lead to overparameterization and computational concerns. To address this issue, the authors use hierarchical priors which reduce the dimension of the parameter vector and allow for dynamic model averaging or selection over TVP-PVARs of different dimension and different priors. Finally, Koop and Korobilis (2015) use forgetting factor methods which greatly reduce the computational burden.

Following the notation of Koop and Korobilis (2015), we denote $Y_{t}=\left(y_{1 t}^{\prime}, y_{2 t}^{\prime}, \ldots, y_{N t}^{\prime}\right)$ for $t=1, \ldots, T$ is the $N G \times 1$ vector of dependent variables where $y_{i t}^{\prime}$ is the $N G \times 1$ vector of dependent (macroeconomic) variables of the cross-sectional unit (country, in our case) $i, i=1, \ldots, N$. The $i$-th equation of the PVAR with $p$ lags takes the form:

$y_{t}=A_{i}^{1} Y_{t-1}+\cdots+A_{i}^{p} Y_{t-p}+u_{i t}$

where $A_{i}^{j}$ for $j=1, \ldots, p$ are $G \times N G$ matrices PVAR coefficients for the country unit $i$. Also $u_{i t}$ is a $N G \times 1$ vector of disturbances, uncorrelated over time, where $u_{i t} \sim N\left(0, \sum_{i i}\right)$. The error between countries may be correlated and we define $E\left(u_{i t} u_{j t}\right) y_{t}=\sum_{i j}$ and $\sum$ to be the entire $N G \times N G$ error covariance matrix for $u_{t}=\left(u_{i t, \ldots,} u_{N t}\right)$.' Let $A^{j}=\left(A_{1}^{j}, \ldots, A_{N}^{j}\right)$ for $j=1, \ldots, p$ and $\alpha=$ $\left(\operatorname{vec}\left(A^{1}\right)^{\prime}, \ldots, \operatorname{vec}\left(A^{p}\right)^{\prime}\right)^{\prime}$. The TVP-PVARs model allows the coefficients in the PVAR to be time varying, therefore all coefficients in $\operatorname{Eq}(1)$ have $t$ subscripts such that $\alpha=\left(\operatorname{vec}\left(A_{t}^{1}\right)^{\prime}, \ldots, \operatorname{vec}\left(A_{t}^{p}\right)^{\prime}\right)^{\prime}$ is the $K \times 1$ vector storing all PVAR parameters at time $t$. The TVP-PVAR model in matrix form can be written as:

$$
Y_{t}=X_{t}^{\prime} \alpha_{t}+u_{t}
$$

where $X_{t}=I \otimes\left(Y_{t-1}^{\prime}, \ldots, Y_{t-p}^{\prime}\right)^{\prime}$, and $u_{i t} \sim N\left(0, \sum_{t}\right)$. In order to reduce the dimension of the TVPVAR, we use DMA methods as described in Koop and Korobilis (2015) by using the following hierarchical prior:

$$
\begin{gathered}
\alpha_{t}=\Xi \theta_{t}+e_{t} \\
\theta_{t}=\theta_{t-1}+\omega_{t},
\end{gathered}
$$

$\alpha_{t}$ is the factor structure for the TVP-VAR coefficients, and $\Xi=\left(\Xi_{1, \ldots .,} \Xi_{q}\right)$ are known materics. $\theta_{t}$ is an $K \times 1$ vector of unknown parameters, and $\omega_{t} \sim N\left(0, W_{t}\right)$ where $W_{t}$ is an $R \times R$ covariance matrix. $^{2}$

\footnotetext{
${ }^{2}$ Please refer to Koop and Korobilis (2015) for detailed description on the estimation and forecasting of TVP-PVAR and DMA.
} 


\section{Data and Results}

In our case, the model has $N$ countries $=12$, and $G$ variables for each country, with the baseline model having output growth, inflation, short-term interest rate and nominal exchange rate growth, to which we add the domestic uncertainty variable, and then the uncertainty variable of the US economy. Hence, $G$ ranges from 4 to 6 , with the baseline 4-variable model being the standard open economy monetary VAR model. Based on data availability to produce a balanced panel, the countries included are Australia, Canada, France, Germany, Ireland, Italy, Japan, South Korea, the Netherlands, Spain, Sweden, and the United Kingdom (UK), covering the monthly period of 2003:03 to 2017:05.

Output growth is measured by month-on-month industrial production growth, whereas monthon-month inflation is derived from the consumer price index, and we also use the month-on-month growth rate of the dollar-based nominal exchange rate to capture movements in the currency market. Data on these three variables comes from the Main Economic Indicators (MEI) Database of the OECD countries. ${ }^{3}$ Barring the Euro area countries (France, Germany, Ireland, Italy, the Netherlands, and Spain), Japan, and the United Kingdom, the short-term interest rate data is derived from OECD's MEI Database for Australia, Canada, South Korea and Sweden. The common short-term interest rate of the Euro area countries, and the individual interest rates of Japan and the UK corresponds to the Shadow Short Rates (SSR) developed by Krippner (2013) based on models of term-structure, and is available for download from the website of the Reserve Bank of New Zealand. ${ }^{4}$ We use the SSR, instead of the standard short-term interest rates for these eight economies, due to the zero lower bound scenario faced by these countries during and post the Great Recession. ${ }^{5}$

Uncertainty is a latent variable, and hence measuring the same is not straight-forward, with many existing approaches (see, Strobel (2015) for a detailed discussion in this regard). However, in line with the above-mentioned studies that have analyzed the forecasting ability of uncertainty for economic activity, and also due to data availability for the multiple countries used in this paper, we rely on the news-based measure of Economic Policy Uncertainty (EPU) index to capture uncertainty. The data on the EPU indices for the twelve countries is based on the work of Baker et al., (2016). ${ }^{6}$ These authors construct indices for major economies of the world by quantifying month-by-month searches for newspaper coverage on terms related to policy-related economic uncertainty. For inclusion in the index, the articles must contain all of the three terms of economy, policy and uncertainty simultaneously. The EPU index is converted into its natural logarithmic form.

We now turn to the results from the model estimated with a lag-length $(p)$ set at 1 , based on the Schwarz Information Criterion (SIC), and an out-of-sample period covering 2009:06 to 2017:05, with 2003:03 to 2009:05 as the in-sample. Note that with one lag, and one observation lost due to data transformation, our effective in-sample starts from 2003:05. This split, allows us to have enough observations for the in-sample estimation to obtain consistent estimators, but is also in line with the periods of global turmoil due to the Great Recession and the European sovereign debt crisis,

\footnotetext{
${ }^{3}$ The data is available for download at: http://www.oecd.org/sdd/oecdmaineconomicindicatorsmei.htm.

${ }^{4}$ The data can be downloaded from the following link: https://www.rbnz.govt.nz/research-and-publications/researchprogramme/additional-research/measures-of-the-stance-of-united-states-monetary-policy/comparison-of-internationalmonetary-policy-measures.

${ }^{5}$ The yield curve-based framework developed by Krippner (2013) essentially removes the effect that the option to invest in physical currency (at an interest rate of zero) has on yield curves, resulting in a hypothetical "shadow yield curve" that would exist if physical currency were not available. The process allows one to answer the question: "what policy rate would generate the observed yield curve if the policy rate could be taken negative?" The "shadow policy rate" generated in this manner, therefore, provides a measure of the monetary policy stance after the actual policy rate reaches zero.

${ }^{6}$ The data can be downloaded from: www.policyuncertainty.com.
} 
with the peak in the domestic EPUs for all of the twelve economies falling in the out-of-sample period.

Table 1 shows the out-of-sample forecasting results for the industrial production growth of the twelve economies over the out-of-sample period for the horizons of one-, three-, six-, and twelvemonth-ahead. The entries in Panel A of Table 1 correspond to the ratio of the Mean Square Forecast Error (MSFE) from the TVP-PVAR model with the individual country EPUs included in the model, relative to the baseline version of the same, which includes the output growth, inflation, short-term interest rate and the growth rate of the exchange rate. Understandably, if this ratio is less than one, then the MSFE from the model with EPU is lower than the MSFE of the baseline model, and hence, EPU produces forecasting gains for economic growth in the twelve economies considered here. As can be seen from the results, forecasting gains are observed for Australia at horizons 1, 3, and 6, for Canada and the Netherlands at one-month-ahead, for France at horizons 6 and 12, for Germany for all horizons barring twelve-month-ahead, for Ireland at all the four horizons considered, for Italy at horizons 1, 3 and 12, for Japan, Spain and Sweden at six-month-ahead only, for South Korea at all horizons barring one-month ahead. The only exception is the UK, for which, unlike in Junttila and Vataja (2017), we do not observe any forecasting gains emanating from the domestic EPU, though similar performance to the baseline model is observed at the horizons of six- and twelve-monthahead.

In panel B of Table 1, we compare the relative MSFEs of the TVP-PVAR model which includes both domestic and US EPUs with the baseline model discussed above. As can be seen, forecasting gains are observed for Australia and Sweden at the one-year-ahead horizon, for Canada at horizons 1 and 3, for France and the Netherlands at horizons 6 and 12, for all the four horizons of Germany, for Ireland at horizons 9 and 12, for Italy at the shortest and the longest horizons, for Japan at horizons 3 and 6, for South Korea all the horizons barring the shortest one, and for Spain at horizon 6. However, comparing across Panels A and B of Table 1, when we look at cases where the TVPPVAR with domestic EPU performs better than the baseline, there are 12 cases $^{7}$ where the TVPPVAR model with both domestic and US EPUs perform better than the model with the baseline variables plus the domestic EPU, with $3 \operatorname{cases}^{8}$ of equal performance. Interestingly, there are 13 scenarios $^{9}$ in which the TVP-PVAR model with domestic EPU only is outperforming the baseline model, as well as the TVP-PVAR model with both domestic and US EPU.

So from an overall perspective, out of the 48 cases considered, adding domestic EPU to the baseline model improves forecasting performances in 22 cases only, i.e., in 45.83 percent of the cases. Also, the US EPU does not necessarily improve the forecasting performance of output growth from the TVP-PVAR model with only the domestic EPU included along with the baseline variables.

\section{[Table 1]}

\section{Conclusion}

In this paper we use a time varying parameter-panel vector autoregressive (TVP-PVAR) model to analyze the role played by domestic and US news-based measures of uncertainty in forecasting the growth of industrial production of twelve (Australia, Canada, France, Germany, Ireland, Italy, Japan,

\footnotetext{
${ }^{7}$ Canada at horizon 1, Germany, Ireland and Sweden at horizon 12, Italy at horizon 1, Japan at horizons 3 and 6, South Korea at horizons 3 and 12, the Netherlands at horizons 9 and 12 and Spain at horizon 9.

${ }^{8}$ At horizon 12 for Australia and France, and for the six-month-ahead forecast of Ireland.

${ }^{9}$ Australia and Ireland at horizons 1 and 3, France at horizon 6, Germany at all horizons barring the longest one, Italy at horizons 3 and 12, South Korea at horizon 6, the Netherlands at horizon 1 and Sweden at horizon 3.
} 
South Korea, the Netherlands, Spain, Sweden, and the UK) Organisation for Economic Cooperation and Development (OECD) countries. Based on a monthly out-of-sample period of 2009:06 to 2017:05, given an in-sample of 2003:03 to 2009:05, we found out that barring the case of UK, there was at least one forecasting horizon of the four (one-, three-, six-, and twelve-monthahead) considered for which domestic uncertainty added value to forecasting growth of industrial production, over and above the information contained in standard predictors (inflation rate, interest rate, and growth of nominal exchange rate). But at the same time, these were only 46 percent of cases relative to the baseline monetary TVP-PVAR model. We not only analyze the impact of the domestic uncertainty of these economies, but also the possible role played by the uncertainty of the US economy, given its dominance in the world economic structure, on the growth of these twelve OECD countries. Moreover, including US uncertainty does not necessarily improve the forecasting performance of output growth from the TVP-PVAR model that includes only the domestic uncertainty along with the baseline variables. So, in general, while uncertainty is important at times in predicting the future path of output growth in the twelve advanced economies considered, a forecaster can do better in majority of the instances by just considering the information from standard macroeconomic variables. In light of these (somewhat mixed) results, it would be interesting to extend our analysis to emerging markets, where the role of uncertainty in driving the economy could be possibly larger (due to their inherent volatile environment), over and above the information conveyed by the standard predictors.

\section{References}

Baker, S., Bloom, N., and Davis, S. (2016). Measuring economic policy uncertainty. Quarterly Journal of Economics, 131, 1593-1636.

Balcilar, M., Gupta, R., and Jooste, C. (2017). Long memory, economic policy uncertainty, and forecasting US inflation: a Bayesian VARFIMA approach. Applied Economics, 49, 1047-1054.

Balcilar, M., Gupta, R., and Segnon, M. (2016). The Role of economic policy uncertainty in predicting U.S. recessions: A mixed-frequency Markov-switching vector autoregressive approach. Economics: The Open-Access, Open-Assessment E-Journal, 10, (2016-27), 1-20.

Campbell, J. Y. (2008). Viewpoint: Estimating the equity premium. Canadian Journal of Economics, 41, 1-21.

Colombo, V. (2013). Economic policy uncertainty in the US: Does it matter for the Euro area? Economics Letters, 121, 39-42.

Gupta, R., Lau, C-K-M., Wohar, M.E. (2018). The impact of US uncertainty on the Euro area in good and bad times: Evidence from a quantile structural vector autoregressive model. Empirica. DOI: https://doi.org/10.1007/s10663-018-9400-3.

Gupta, R., Ma, J., Risse, M., and Wohar, M.E. (Forthcoming). Common Business Cycles and Volatilities in US States and MSAs: The Role of Economic Uncertainty. Journal of Macroeconomics. 
Jones, P. M., and Olson, E. (2015). The international effects of US uncertainty. International Journal of Finance and Economics, 20, 242-252.

Junttila, J-P., and Vataja, J. (2017). A random walk down the economic policy street: Effects of economic policy uncertainty on forecasting future real economic activity in the Euro area and the UK. Working Paper, Available at SSRN: https://ssrn.com/abstract=2919400.

Karnizova, L. and Li, J. C. (2014). Economic policy uncertainty, financial markets and probability of US recessions. Economics Letters, 125, 261-265.

Koop, G., and Korobilis, D. (2015). Forecasting with high dimensional panel VARs. Working Papers 2015_25, Business School - Economics, University of Glasgow.

Krippner, L. (2013). A Tractable Framework for Zero Lower Bound Gaussian Term Structure Models. Discussion Paper, Reserve Bank of New Zealand, 2013/02.

Pierdzioch, C., and Gupta, R. (2017). Uncertainty and Forecasts of U.S. Recessions. Department of Economics, University of Pretoria, Working Paper No. 201732.

Segnon, M., Gupta, R., Bekiros, S., and Wohar, M.E. (forthcoming). Forecasting US GNP growth: The role of uncertainty. Journal of Forecasting.

Strobel, J. (2015). On the different approaches of measuring uncertainty shocks. Economics Letters, 134, 69-72. 
Table 1: Mean Square Forecast Errors (MSFEs) for Growth of Industrial Production from TVP-PVAR Model Relative to the Baseline

\begin{tabular}{|c|c|c|c|c|c|c|c|c|c|c|c|c|}
\hline \multirow{2}{*}{$\begin{array}{l}\text { Panel A: } \\
\text { Horizon }\end{array}$} & \multicolumn{12}{|c|}{ Baseline Model with Domestic EPU } \\
\hline & Australia & Canada & France & Germany & Ireland & Italy & Japan & South Korea & $\begin{array}{c}\text { The } \\
\text { Netherlands }\end{array}$ & Spain & Sweden & UK \\
\hline 1 & 0.992 & 0.974 & 1.022 & 0.972 & 0.991 & 0.994 & 1.002 & 1.012 & 0.995 & 1.016 & 1.006 & 1.012 \\
\hline 3 & 0.985 & 1.000 & 1.006 & 0.985 & 0.997 & 0.983 & 1.003 & 0.993 & 1.020 & 1.038 & 1.011 & 1.014 \\
\hline 6 & 1.015 & 1.029 & 0.970 & 0.984 & 0.993 & 1.006 & 0.997 & 0.978 & 1.002 & 0.978 & 0.995 & 1.000 \\
\hline 12 & 0.977 & 1.000 & 0.994 & 1.018 & 0.997 & 0.987 & 1.020 & 0.993 & 1.007 & 1.031 & 1.012 & 1.000 \\
\hline \multicolumn{13}{|c|}{ Panel B: Baseline Model with Domestic EPU and US EPU } \\
\hline Horizon & Australia & Canada & France & Germany & Ireland & Italy & Japan & South Korea & $\begin{array}{c}\text { The } \\
\text { Netherlands }\end{array}$ & Spain & Sweden & UK \\
\hline 1 & 1.008 & 0.974 & 1.022 & 0.989 & 1.016 & 0.994 & 1.008 & 1.004 & 1.011 & 1.033 & 1.009 & 1.000 \\
\hline 3 & 1.000 & 0.991 & 1.012 & 0.990 & 1.009 & 1.006 & 0.987 & 0.989 & 1.015 & 1.053 & 1.014 & 1.000 \\
\hline 6 & 1.015 & 1.010 & 0.988 & 0.989 & 0.993 & 1.000 & 0.988 & 0.989 & 0.974 & 0.957 & 1.000 & 1.014 \\
\hline 12 & 0.977 & 1.000 & 0.994 & 0.988 & 0.980 & 0.994 & 1.033 & 0.979 & 0.991 & 1.031 & 0.990 & 1.000 \\
\hline
\end{tabular}

Note: Entries in bold correspond to cases where the TVP-PVAR with measures of uncertainty outperforms the baseline model, as the relative MSFEs are less than one. 